Nursenem Karaca, Görkem Şener, Betül Demirci and Fatih Demirci*

\title{
Synergistic antibacterial combination of Lavandula latifolia Medik. essential oil with camphor
}

https://doi.org/10.1515/znc-2020-0051

Received March 13, 2020; accepted October 16, 2020;

published online November 2, 2020
Keywords: antibacterial activity; camphor; checkerboard method; Lavandula latifolia; synergistic.

\section{Introduction}

Lavandula sp. (Lamiaceae) is a valuable essential oil plant crop, which is cultivated around the world mainly for cosmetics and pharmaceutical utilization since centuries $[1,2]$. Lavandula essential oils are especially used for nervous system stimulation, sedation, tranquilization and stress relieve. In addition, it has useful dermatological uses in the treatment of sunburn and skin rashes, as well as strong antiseptic, and antimicrobial effects [3]. There are 39 Lavandula species, which are mostly of Mediterranean origin. However, there are three commercially important species within the genus among other cultivars, producing lavender (Lavandula angustifolia Mill. $=L$. officinalis $\mathrm{L} .=L$. vera $\mathrm{DC}$ ), lavandin (L. intermedia Emeric ex Loisel. $=$ L. hybrida L. $)$ and Spike lavender $(L$. spica $=$ Lavandula latifolia Medik.) $[4,5]$.

L. latifolia Medik. essential oil is one of the medicinal herbal products, which contains as main components 1,8-cineole and linalool, having utilization in cosmetics and pharmaceuticals as well. Linalool has sedative $[6,7]$ and local anesthetic effects [8]; antimicrobial [9, 10], and insecticidal effects [11, 12]; whereas the main component 1,8-cineole has antispasmodic [13] and antimicrobial [10] properties. 1,8-Cineole is also present in L. angustifolia and L. hybrida, although in much lower concentrations [14-16].

The study material camphor is a white crystalline monoterpene, generally obtained from the tropical Cinnamonum camphora tree, if not from synthetic origin from turpentine. In addition, camphor is found in many essential oils including Lavandula sp., Artemisia sp., Rosmarinus officinalis etc. Camphor is traditionally used to treat colds, pain and inflammation. In vitro antiviral, anticancer, anti-inflammatory, analgesic, antispasmodic, nasal decongestant and rubefacient effects are also reported. The use of $3-11 \%$ as a topical pain reliever and anesthetic is approved by the FDA. Also, it is well known that the enantiomeric structure of essential oil components such as camphor affects the bioactivity results, each enantiomer Pharmacognosy, Faculty of Pharmacy, Anadolu University, 26470, Eskişehir, Turkey; and Faculty of Pharmacy, Eastern Mediterranean University, Famagusta, 99628, N.Cyprus, Mersin 10, Turkey, E-mail: fdemirci@anadolu.edu.tr. http://orcid.org/0000-0003-1497-3017 Nursenem Karaca and Görkem Şener, Graduate School of Health Sciences, Department of Pharmacognosy, Anadolu University, Eskişehir, Turkey

Betül Demirci, Department of Pharmacognosy, Faculty of Pharmacy, Anadolu University, 26470, Eskişehir, Turkey 
may have different activity and effects. However, overdose may cause toxic effects, especially in children, which urges careful use [17, 18].

The selected microorganisms of the present study; Staphylococcus aureus is among the human pathogens causing a wide spectrum of diseases such as respiratory tract infections, endocarditis, arthritis among others [19], whereas Listeria monocytogenes is a foodborne pathogen, and its infection may cause brain invasion, listeriosis resulting fewer, diarrhea and muscle aches etc. [20, 21].

Side effects of drugs and antimicrobial resistance caused using excessive and unnecessary antibiotics require the development of new antimicrobials [22, 23]. Recently, efforts to increase antimicrobial activity have gained importance with the combination of essential oils with natural ingredients and standard antibiotics [24, 25].

The aim of this work was to compare the antimicrobial efficacy by using binary combinations of $L$. latifolia essential oil with racemic camphor, alone and in combination using the checkerboard method, against human pathogenic $S$. aureus and L. monocytogenes standard strains.

\section{Materials and methods}

\subsection{Materials}

Pharma-grade [26] L. latifolia essential oil was purchased at Apoth. Bauer \& Co., Germany. ( \pm )-Camphor (Ph. Eur., $\geq 95 \%$ ) and other chemicals were acquired from Sigma-Aldrich, Merck, Fluka if not otherwise indicated.

\subsection{Analytical}

2.2.1 Gas chromatography/mass spectrometry (GC/MS): The analyses were carried out using the Agilent 5975 GC-MSD system (Sem Ltd., Istanbul, Turkey). Innowax FSC column $(60 \mathrm{~m} \times 0.25 \mathrm{~mm}, 0.25 \mu \mathrm{m}$ film thickness) was used with helium as carrier gas ( $0.8 \mathrm{~mL} / \mathrm{min})$. GC oven temperature was kept at $60{ }^{\circ} \mathrm{C}$ for $10 \mathrm{~min}$ and programmed to $220^{\circ} \mathrm{C}$ at a rate of $4^{\circ} \mathrm{C} / \mathrm{min}$ and kept constant at $220^{\circ} \mathrm{C}$ for $10 \mathrm{~min}$ and then programmed to $240{ }^{\circ} \mathrm{C}$ at a rate of $1{ }^{\circ} \mathrm{C} / \mathrm{min}$. Split ratio was adjusted at 40:1. The injector temperature was set at $250{ }^{\circ} \mathrm{C}$. Mass spectra were recorded at $70 \mathrm{eV}$, where the mass range was from $\mathrm{m} / z 35$ to 450 .

2.2.2 Gas chromatography-flame ionization detector (GC-FID): The GC analyses were carried out using an Agilent 6890 N GC system (Sem Ltd., Istanbul, Turkey). Flame ionization detector (FID) temperature was set to $300{ }^{\circ} \mathrm{C}$. To obtain the same elution order with the GC/MS system, simultaneous auto-injection was done on a duplicate of the same column applying the same operational conditions. Relative percentages (\%) of the separated compounds were calculated from FID chromatograms.
Table 1: Lavandula latifolia essential oil analysis, relative percentages (\%).

\begin{tabular}{llrl}
\hline RRI & Compounds & $\%$ & IM \\
\hline 1032 & $\alpha$-pinene & 2.4 & RRI, MS \\
1076 & Camphene & 0.5 & RRI, MS \\
1118 & $\beta$-pinene & 2.0 & RRI, MS \\
1174 & Myrcene & 0.4 & RRI, MS \\
1203 & Limonene & 1.3 & RRI, MS \\
1213 & 1,8-cineole & 25.6 & RRI, MS \\
1246 & (Z)- $\beta$-ocimene & 0.1 & MS \\
1255 & -terpinene & tr & RRI, MS \\
1266 & (E)- $\beta$-ocimene & 0.1 & MS \\
1280 & $p$-cymene & 0.6 & RRI, MS \\
1532 & Camphor & 12.2 & RRI, MS \\
1553 & Linalool & 45.2 & RRI, MS \\
1565 & linalyl acetate & 2.3 & RRI, MS \\
1612 & $\beta$-caryophyllene & 1.0 & RRI, MS \\
1611 & terpinen-4-ol & 0.2 & RRI, MS \\
1617 & lavandulyl acetate & 0.1 & RRI, MS \\
1684 & Isoborneol & 0.5 & MS \\
1706 & $\alpha$-terpineol & 1.5 & RRI, MS \\
1719 & Borneol & 0.9 & RRI, MS \\
1733 & neryl acetate & 0.3 & RRI, MS \\
1795 & geranyl acetate & tr & RRI, MS \\
1808 & Nerol & 0.2 & RRI, MS \\
1857 & Geraniol & 0.4 & RRI, MS \\
2008 & caryophyllene oxide & 0.2 & RRI, MS \\
Total & & 97.9 & \\
\hline & & & \\
\hline
\end{tabular}

RRI: Relative retention indices calculated against $n$-alkanestr. tr: Trace ( $<0.1 \%$ ). IM: Identification method based on the relative retention indices (RRI) of authentic compounds on the HP Innowax column; MS, identified on the basis of computer matching of the mass spectra with those of the Wiley and MassFinder libraries and comparison with literature data.

2.2.3 Identification of the components: Identification of the essential oil components was carried out by comparison of their relative retention times (RT) with those of authentic samples or by comparison of their relative retention index (RRI) to that of a series of $n$-alkanes. Computer matching against commercial (Wiley GC/MS Library, MassFinder 4 Library) and in-house "Başer Library of Essential Oil Constituents" libraries built up by genuine compounds and components of known oils as well as MS literature data was used [25, 27]. Results are given in Table 1.

\subsection{Antibacterial activity}

2.3.1 Bacterial strains: S. aureus ATCC 25923 and L. monocytogenes ATCC 19111 were obtained from the American Type Culture Collection (ATCC). All microorganisms were stored at $-85^{\circ} \mathrm{C}$ in $15 \%$ glycerol prior to the experiments. Bacterial strains were refreshed on Mueller Hinton Agar (MHA, Merck) plates at $37^{\circ} \mathrm{C}$. Strains were inoculated and standardized versus McFarland No: 0.5 turbidimetrically in sterile saline $(0.85 \%)$ to $5 \times 10^{3} \mathrm{CFU} /$ per well in Mueller Hinton Broth (SigmaAldrich) [29]. 
2.3.2 In vitro antibacterial activity by microdilution method: The lavender essential oil and camphor were evaluated for their potential antibacterial activity by using the microdilution broth susceptibility assay [27, 28, 30]. Essential oil and camphor dilution series were prepared in 96-well microtiter plates at a concentration range of 0.16$20 \mathrm{mg} / \mathrm{mL}$. About $100 \mu \mathrm{L}$ of 1:100 diluted bacterial suspensions were then added to each well. The last row containing medium with microorganism was used as negative control and the well containing only medium served as a positive growth control. Clarithromycin $(0.125-16 \mu \mathrm{g} / \mathrm{mL})$ was used for standard antimicrobial. The microplates were covered with airtight films just before they were placed in the incubator. After incubation at $37^{\circ} \mathrm{C}$ for $24 \mathrm{~h}$, for staining of viable microorganisms, $20 \mu \mathrm{L}$ of resazurin of $0.01 \%$ was added to all the plates. The first blue well was determined as the minimal inhibitory concentration (MIC, $\mathrm{mg} / \mathrm{mL}$ ). All experiments were repeated in triplicate, and average MICs were reported in Table 2.

2.3.3 In vitro synergistic antibacterial activity by checkerboard method: Serial dilutions of the samples were prepared. About $50 \mu \mathrm{L}$ dilutions of the first test substance (L. latifolia essential oil) were added to the microtiter plate from A to $\mathrm{H}$, while $50 \mu \mathrm{L}$ dilutions of the other test substance (camphor) were added vertically from 1 to 8 . About $100 \mu \mathrm{L}$ 1:100 diluted bacterial suspensions were then added to each well. After $24 \mathrm{~h}$ of incubation at $37^{\circ} \mathrm{C}, 20 \mu \mathrm{L}$ of $0.01 \%$ resazurin solution was added onto the Petri dish for visualization. The microplates were covered with airtight films just before they were placed in the incubator. The incubation was continued for $3 \mathrm{~h}$ at $37^{\circ} \mathrm{C}$. The determined MIC values were used for fractional inhibition concentration (FIC) calculation following the formula:

$$
\operatorname{FIC}(A+B)=(\operatorname{MICAB} / M I C A)+(\operatorname{MICAB} / M I C B) .
$$

The results were interpreted as synergistic (FIC $<0.5$ ), additive $(0.5 \leq \mathrm{FIC} \leq 1)$, indifference $(1<\mathrm{FIC} \leq 4)$ or antagonism (FIC > 4) $[25,31]$, as shown in Table 2.

\section{Results and discussion}

\subsection{Chemical components of $L$. latifolia essential oil}

For the verification of the pharmacopoeia quality, the essential oil was analyzed by both GC/FID and GC-MS, simultaneously. A total of 24 of the main components were detected in L. latifolia essential oil, with a ratio of $97.9 \%$. In this present study, the major compounds of the spike lavender essential oil were identified as linalool (45.2\%), 1,8-cineole (25.6\%) and camphor (12.2\%) confirming the quality, which confirms the Ph. Eur. 9.0 [26] and are listed in Table 1.

According to previous literature, major compounds of L. latifolia essential oils are reported as linalool 41.0-43.2\%, camphor 12.5-13.0\%, 1,8-cineole 11-27\% [32, 33]. In a recent study, chemical analyses of spike lavender essential oil from Spain were reported, where linalool (32.3\%), 1,8-cineole $(11.7 \%)$ and camphor (12.4\%) were determined as main components [34]. In the study reported by Carrasco et al. 2016, linalool (35-51\%), 1,8-cineole (26-32\%) and camphor (10-18\%), respectively, were identified as the main components for L. latifolia essential oil [35].

\subsection{Antimicrobial activity}

Initially, antibacterial activity of the essential oil, camphor (MIC range: $0.16-20 \mathrm{mg} / \mathrm{mL}$ ) and standard antimicrobial

Table 2: Minimum inhibitory concentrations (MIC, $\mathrm{mg} / \mathrm{mL}$ ) and fractional inhibitory concentrations (FIC) of essential oil and camphor combinations determined by checkerboard microdilution method.

\begin{tabular}{|c|c|c|c|c|c|c|c|}
\hline \multirow[t]{2}{*}{ Standard strains } & \multicolumn{5}{|r|}{ MIC } & \multirow[t]{2}{*}{ FIC } & \multirow[t]{2}{*}{ Effect } \\
\hline & Clarithromycin $(\mu \mathrm{g} / \mathrm{mL})$ & Essential oil & Camphor & $\begin{array}{r}\text { Combination of } \\
\text { essential oil }\end{array}$ & $\begin{array}{r}\text { Combination of } \\
\text { camphor }\end{array}$ & & \\
\hline \multirow[t]{5}{*}{ L. monocytogenes } & 0.125 & 1.25 & 2.5 & 0.62 & 0.31 & 0.6 & additive \\
\hline & & & & 0.62 & 0.62 & 0.7 & additive \\
\hline & & & & 0.31 & 0.62 & 0.5 & additive \\
\hline & & & & 0.16 & 0.62 & 0.4 & synergistic \\
\hline & & & & 0.08 & 0.62 & 0.3 & synergistic \\
\hline \multirow[t]{10}{*}{ S. aureus } & 0.25 & 2.5 & 5 & 1.25 & 0.31 & 0.5 & additive \\
\hline & & & & 1.25 & 0.62 & 0.6 & additive \\
\hline & & & & 1.25 & 1.25 & 0.7 & additive \\
\hline & & & & 1.25 & 2.5 & 1.0 & additive \\
\hline & & & & 0.62 & 1.25 & 0.5 & additive \\
\hline & & & & 0.62 & 2.5 & 0.7 & additive \\
\hline & & & & 0.31 & 1.25 & 0.4 & synergistic \\
\hline & & & & 0.31 & 2.5 & 0.6 & additive \\
\hline & & & & 0.16 & 2.5 & 0.6 & additive \\
\hline & & & & 0.08 & 2.5 & 0.5 & additive \\
\hline
\end{tabular}


clarithromycin (MIC range: $0.125-16 \mu \mathrm{g} / \mathrm{mL}$ ) were determined by in vitro microdilution method against $S$. aureus and $L$. monocytogenes, respectively. The results of the antibacterial activity as MIC values were listed in Table 2 . Accordingly, in this method, essential oil and camphor were effective at 2.5 and $5 \mathrm{mg} / \mathrm{mL}$ against $S$. aureus and 1.25 and $2.5 \mathrm{mg} / \mathrm{mL}$ against L. monocytogenes pathogen, respectively.

The antimicrobial effect of the lavender essential oil was previously reported, where the agar dilution results showed MIC values 0.2 and $>0.8 \%$ (vol/vol) against $S$. aureus and L. monocytogenes strains, respectively [36]. The inhibitory activity of L. latifolia essential oil against $S$. aureus and L. monocytogenes strains was reported in the concentration range of $0.5-2 \mu \mathrm{L} / \mathrm{mL}$ [37]. In another publication, the effect of $L$. latifolia essential oil vapor against $S$. aureus showed no effect at a test concentration of $500 \mu \mathrm{L} / \mathrm{L}$ [38].

Overall, 64 different essential oil + camphor combinations were evaluated against $S$. aureus, and $L$. monocytogenes using the checkerboard microdilution method. Results of combination tests with the checkerboard assay are shown in Table 2. Synergistic effects were observed from $0.16+0.62$ and $0.08+0.62(\mathrm{mg} / \mathrm{mL})$ essential oil + camphor combinations against $L$. monocytogenes and $0.31+1.25(\mathrm{mg} / \mathrm{mL})$ against $S$. aureus. In addition to the synergistic effects, additive effects were observed against the particular studied microorganisms.

De Rapper and coworkers (2013) analyzed the antimicrobial activity of $L$. angustifolia essential oil in combination with other 45 essential oils against pathogenic microorganisms like $S$. aureus, Pseudomonas aeruginosa and Candida albicans, and reported that the combinations showed $26.7 \%$ synergistic, and $48.9 \%$ additive effects [39]. Magi et al. 2015 evaluated the in vitro antibacterial activity of L. angustifolia, Origanum vulgare, Thymus vulgaris, Mentha piperita, and Melaleuca alternifolia essential oils; as well as carvacrol, and synergy of carvacrol and erythromycin, against 32 clinical, erythromycin-resistant groups of Streptococci [40]. Stevic et al. 2014 determined antifungal synergistic effects, with lavender-rose oil and lavender-oregano oil against Fusarium subglutinans and F. semitectum [41].

Camphor was present in the tested L. latifolia essential oil, in relatively high amounts. The combination of L. latifolia essential oil and racemic camphor indeed increases the relative amount, which may have an impact to the antimicrobial effects. To confirm the combination effects of camphor on an essential oil, more detailed work is needed such as using an essential oil without camphor content.

As a result, additive and synergistic effects of $L$. latifolia essential oil and the monoterpene camphor were demonstrated for the first time, with an overall success rate of $23.4+4.7 \%$, respectively. The results also suggested that approx. $72 \%$ of the random mixtures lead to "indifferent activity" outcomes. Essential oil + camphor combinations were identified as "synergistic (FIC $\leq 0.5)$ and additive $(0.5<\mathrm{FIC} \leq 1)$ " in the respective combinations, suggesting a positive impact on antimicrobial activity holding promise for future in-depth formulation studies.

\section{Conclusion}

One of the current approaches toward synergic antimicrobial combination evaluation is the in vitro checkerboard method used in this present study. As observed in the present study, L. latifolia and camphor combinations were relatively more inhibitory against the pathogens $L$. monocytogenes and S. aureus, respectively. For safe future utilization in formulations, more detailed in vitro and in vivo toxicological evaluations are suggested and needed.

Acknowledgments: This work was supported by Anadolu University Project BAP1604S160. Part of this work was presented at the 48th International Symposium on Essential Oils (ISEO2017), Pecs, Hungary.

Author contribution: All the authors have accepted responsibility for the entire content of this submitted manuscript and approved submission.

Research funding: This work was supported by Anadolu University Project BAP1604S160.

Conflict of interest statement: The authors declare no conflicts of interest regarding this article.

\section{References}

1. Buchbauer G. Lavender oil and its therapeutic properties. In: Lis-Balchin $M$, editor. Lavender the genus lavandula. New-York: CRC Press, Taylor and Francis; 2002: 124-39 pp.

2. Başer KHC, Buchbauer G. Handbook of essential oils: Science, technology, and applications, 2nd ed. USA: CRC Press, Taylor and Francis; 2016.

3. Cavanagh HM, Wilkinson JM. Biological activities of lavender essential oil. Phytother Res 2002;16:301-8.

4. Tucker AO. Lavender, spike and lavandin. Herbarist 1985;51: 44-50.

5. Lis-Balchin M. Lavender: the genus Lavandula, Medicinal and aromatic plants-industrial profiles. New-York: CRC Press, Taylor and Francis; 2002.

6. Buchbauer G, Jirovetz L, Jager W, Dietrich H, Plank C. Aromatherapy: evidence for sedative effects of the essential oil of lavender after inhalation. Z Naturforsch C 1991;46: 1067-72. 
7. Sugawara Y, Hara C, Tamura K, Fujii T, Nakamura KI, Masujima T, et al. Sedative effect on humans of inhalation of essential oil of linalool: sensory evaluation and physiological measurements using optically active linalools. Anal Chim Acta 1998;365:293-9.

8. Ghelardini C, Galeotti N, Salvatore G, Mazzanti G. Local anaesthetic activity of the essential oil of Lavandula angustifolia. Planta Med 1999;65:700-3.

9. Gabbrielli G, Loggini G, Cioni P, Giannaccini B, Mancuso E. Activity of lavandin essential oil against non-tubercular opportunistic rapid grown mycobacteria. Pharmacol Res Commun 1988;20.

10. Pattnaik S, Subramanyam VR, Bapaji M, Kole CR. Antibacterial and antifungal activity of aromatic constituents of essential oils. Microbios 1997;89:39-46.

11. Yarnell E. Essential oils against lice. Q Rev Nat Med 1998;3: 177-84.

12. Perrucci S, Cioni PL, Flamini G, Morelli I, Macchioni G. Acaricidal agents of natural origin against Psoroptes cuniculi. Parasitologia 1994;36:269-71.

13. Plamen S, Julian L, André-Michael B. Effects of 1.8-cineole (eucalyptol) on the spontaneous contractile activity of smooth muscles fibre. J Med Plants Res 2015;9:486-93.

14. Wobben HJ, ter Heide R, Rimmer R. Investigation into the composition of Spanish spike lavender oil. Soap Perfum Cosmet 1969;42:739-40.

15. Bissett NG. Herbal drugs and phytopharmaceuticals. Stuttgart: MedPharm CRC Press; 1994:566 p.

16. Peracino V, Caramiello R, Maffei M. Essential oils from same Lavandula hybrids growing spontaneously in North West Italy. Flavour Fragr J 1994;9:11-7.

17. Zuccarini P. Camphor: risks and benefits of a widely used natural product. JASEM 2009;13.

18. Hamidpour R, Hamidpour S, Hamidpour M, Shahlari M. Camphor (Cinnamomum camphora), a traditional remedy with the history of treating several diseases. Int J Case Rep Images 2013;4:86-9.

19. Lowy FD. Staphylococcus aureus infections. N Engl J Med 1998; 339:520-32.

20. Drevets DA, Bronze MS. Listeria monocytogenes: epidemiology, human disease, and mechanisms of brain invasion. FEMS Immunol Med Microbiol 2008;53:151-65.

21. Low JC, Donachie W. A review of Listeria monocytogenes and listeriosis. Vet J 1997;153:9-29.

22. Watkins RR, Holubar M, David MZ. Antimicrobial resistance in methicillin-resistant Staphylococcus aureus to newer antimicrobial agents. Antimicrob Agents Chemother 2019;63.

23. Furuya-Kanamori L, Yakob L. Filling the gaps in global antimicrobial resistance research/surveillance. BMC Infect Dis 2020;20:39.

24. Langeveld WT, Veldhuizen EJ, Burt SA. Synergy between essential oil components and antibiotics: a review. Crit Rev Microbiol 2014; 40:76-94.

25. Göger G, Demirci B, Ilgın S, Demirci F. Antimicrobial and toxicity profiles evaluation of the chamomile (Matricaria recutita L.) essential oil combination with standard antimicrobial agents. Ind Crops Prod 2018;120:279-85.
26. Ph Eur. 9.0, European Pharmacopoeia, 9th ed. Strasbourg: Council of Europe; 2016.

27. Karaca N, Demirci B, Demirci F. Evaluation of Lavandula stoechas L. subsp. stoechas L, Mentha spicata L. subsp. spicata L. essential oils and their main components against sinusitis pathogens. Z Naturforsch C 2018;73:353-60.

28. Demirci F, Karaca N, Tekin M, Demirci B. Anti-inflammatory and antibacterial evaluation of Thymus sipyleus Boiss. subsp. sipyleus var. sipyleus essential oil against rhinosinusitis pathogens. Microb Pathog 2018;122:117-21.

29. CLSI. Performance standards for antimicrobial susceptibility testing; seventeenth informational supplement, M100-S17. Clin Lab Stand Inst 2007;27.

30. CLSI. Methods for dilution antimicrobial susceptibility tests for bacteria that grow aerobically; approved standard, M7-A7. Clin Lab Stand Inst 2006;26.

31. van Vuuren S, Viljoen A. Plant-based antimicrobial studiesmethods and approaches to study the interaction between natural products. Planta Med 2011;77:1168-82.

32. Barazandeh MM. Essential oil composition of Lavandula latifolia Medik from Iran. J Essent Oil Res 2002;14:2.

33. Munoz-Bertomeu J, Arrillaga I, Segura J. Essential oil variation within and among natural populations of Lavandula latifolia and its relation to their ecological areas. Biochem Syst Ecol 2007;35: 479-88.

34. Alatrache A, Jamoussi B, Tarhouni R, Abdrabba M. Analysis of the essential oil of Lavandula latifolia from Tunisia. J Essent Oil-Bear Plants 2007;10:446-52.

35. Carrasco A, Martinez-Gutierrez R, Tomas V, Tudela J. Lavandula angustifolia and Lavandula latifolia essential oils from Spain: aromatic profile and bioactivities. Planta Med 2016;82:163-70.

36. Oussalah M, Caillet S, Saucier L, Lacroix M. Inhibitory effects of selected plant essential oils on the growth of four pathogenic bacteria: E. coli 0157:H7, Salmonella typhimurium, Staphylococcus aureus and Listeria monocytogenes. Food Contr 2007;18:414-20.

37. Rota C, Carraminana JJ, Burillo J, Herrera A. In vitro antimicrobial activity of essential oils from aromatic plants against selected foodborne pathogens. J Food Prot 2004;67:1252-6.

38. Kloucek P, Smid J, Frankova A, Kokoska L, Valterova I, Pavela R. Fast screening method for assessment of antimicrobial activity of essential oils in vapor phase. Food Res Int 2012;47:161-5.

39. De Rapper S, Kamatou G, Viljoen A, van Vuuren S. The in vitro antimicrobial activity of Lavandula angustifolia essential oil in combination with other aroma-therapeutic oils. Evid Based Complement Alternat Med 2013:852049.

40. Magi G, Marini E, Facinelli B. Antimicrobial activity of essential oils and carvacrol, and synergy of carvacrol and erythromycin, against clinical, erythromycin-resistant Group A Streptococci. Front Microbiol 2015;6:165.

41. Stevic T, Beric T, Savikina K, Sokovic M, Godevac D, Dimkic I, et al. Antifungal activity of selected essential oils against fungi isolated from medicinal plant. Ind Crops Prod 2014;55:116-22.

Supplementary Material: The online version of this article offers supplementary material (https://doi.org/10.1515/znc-2020-0051). 